\title{
Specific surfaces and heat of adsorption of some Indian clays by dye-adsorption technique
}

\author{
S K DAS and M K CHATTERJEE* \\ National Metallurgical Laboratory (CSIR), Jamshedpur 831007 , India \\ * Department of Chemical Technology, University of Calcutta, Calcutta 700009 , India \\ MS received 4 November 1992; revised 18 February 1993
}

\begin{abstract}
Adsorption of basic dye methylene blue by some Indian clays has been studied. BET plotting of the adsorption isotherms was applied to determine the specific surfaces of clays and heat of adsorption. About $10-20 \%$ lower values of specific surfaces were obtained when compared with the most accurate gas-adsorption BET results and its probable reasons discussed. The calculated heat of adsorption values confirm the physical adsorption.
\end{abstract}

Keywords. Dye-adsorption; clay-dye system; heat of adsorption; specific surfaces of clays; BET plot of adsorption isotherm.

\section{Introduction}

The knowledge of specific surfaces of clays is essential to control the industrial production of clay-based articles. Several factors are associated with the specific surfaces of clays due to their inhomogeneous nature and this greatly depends on the origin of the clay and methods of measuring. Many conventional methods are available to determine specific surfaces of clays e.g. turbidimetry, permeability, microscopic observation, particle size analysis, gas-adsorption, etc. Of these, gas-adsorption technique is considered to be the most accurate and reliable method to measure the total surface area of clay. However, it may not be possible for many of the clay industries to implement gas-adsorption technique due to its complexity and costly set of apparatus. Also other accepted simple and quick methods are available in literature like glycol-retention method (Dyal and Hendricks 1950; Amerongen 1967), solute adsorption from solution (Ewing and Rhoda 1950; Maron et al 1956) etc. Basic dye-adsorption technique is also often suggested (Worrall 1958; White and Cowan 1960; Boardman and Worrall 1965) for determining specific surfaces of clays and the use of dye-solutions offers a very simple and economic technique. Large organic cation and a simple anion are produced when a basic dye in solution ionizes. Worrall (1958) who studied the adsorption of basic dye by clays reported that clay attracts dye cation due to its cation-exchange capacity and dye tends to displace completely the initial cations on the clays in aqueous solution because of their organic nature. On the basis of the above theory and a series of experimental evidences, Worrall (1958) concluded that adsorption of basic dye methylene blue by clays was primarily by cation exchange and this was physical only when the adsorption continued beyond the cation exchange capacity. White and Cowan (1960) further reported that total area of the clay was covered once the physical adsorption occurred and this was based on the fact that methylene blue was larger in size than a base exchange site. Using the basic dye adsorption technique, Boardman and Worrall (1965) discussed that this method measured those specific surfaces of clays which were within $\pm 10 \%$ of BET (Brunauer et al 1938) gas adsorption values and there might have been an 
error of as high as $50 \%$. Various opinions and limitations of measuring specific surfaces of clays from clay-dye adsorption behaviour are cited in literature (Orr and Dallavalle 1959; Faruqi et al 1967). The above work revealed that most researchers accepted the dye-adsorption technique to measure the surface area of clays due to its simplicity and quick approach provided no greater accuracy is required and may be adopted qualitatively for comparison. This concept of clay-dye adsorption phenomenon was also used by some workers (Gand 1989; Lautrin 1989) for better identification of clayey soils and rapid determination of fines at construction sites using methylene blue. Although, methylene blue dye was commonly used earlier to understand the clay-dye adsorption behaviour, Yariv et al (1991) recently studied the adsorption of other cationic dyes such as crystal violet and ethyl violet by kaolinite. In the present investigation, an attempt has been made to standardize the dyeadsorption method of measuring specific surfaces of some Indian clays which may be economically useful to industries for selection of suitable clays for various types of clay-based articles. The study also determines the heat of adsorption to know the nature of adsorption in the present clay-dye system.

\section{Process of calculations}

The most widely used mathematical statement of BET theory in case of vapour adsorption is expressed in the following equation

$$
x / x_{m}=\frac{K\left(P / P_{s}\right)}{\left(1-P / P_{s}\right)\left[1-P / P_{s}+K\left(P / P_{s}\right)\right]}
$$

On rearrangement, the above equation becomes (Turkdogan et al 1970)

$$
P / x\left(P_{s}-P\right)=\frac{1}{x_{m} \cdot K}+\frac{K-1}{x_{m} \cdot K} \cdot \frac{P}{P_{s}}
$$

where $x$ is the quantity of vapour adsorbed at vapour pressure $P, x_{m}$, the quantity of adsorbate required for a complete condensed layer on the solid, the layer being one molecule deep, $P_{s}$, the saturated vapour pressure and $K$, the constant, related to heat of adsorption.

In case of liquid (dye) adsorption, (2) can be rewritten as

$$
C / x\left(C_{0}-C\right)=\frac{1}{x_{m} \cdot K}+\frac{K-1}{x_{m} \cdot K} \cdot \frac{C}{C_{0}},
$$

where $C_{0}$ is the initial concentration of the solution used, $C$, the final concentration of the solution, $x$, the amount of dye adsorbed and $x_{m}$, the quantity of adsorbate required for a complete monolayer on the solid. Equation (3) shows that the plot of experimental values for $C / x\left(C_{0}-C\right)$ against $C / C_{0}$ gives a straight line. The slope of this line is $K-1 /\left(x_{m} \cdot K\right)$ and the intercept on the $Y$-axis is $1 /\left(x_{m} \cdot K\right)$. Combination of slope and intercept yields

$$
x_{m}=1 /(\text { slope }+ \text { intercept) }
$$

Hence, after knowing the intercept and slope values, the values of $x_{m}$ and $K$ are determined. 
In the present study, the $C_{0}$ and $C$ units are reported as molar per $1000 \mathrm{ml}$ and $x$ is in milli-equivalent per $100 \mathrm{~g}$ (meq. $/ 100 \mathrm{~g}$ ). Hence $X_{m}$ is also obtained in meq. $/ 100 \mathrm{~g}$. Now, considering the surface area $(S)$ of the adsorbent as equal to the product of the number of adsorbed molecules in the first layer and the area covered by a single molecule,

$$
S=\left(x_{m} \cdot N / 10^{5}\right) \cdot a_{1} \cdot 10^{-20} \mathrm{~m}^{2} / \mathrm{g}
$$

where $N$ is the Avogadro's number $6.60 \times 10^{23}$ and $a_{1}$, the surface covered by a single adsorbed molecule. As in connection with the basic dye-adsorption, White and Cowan (1960) assumed that in its most dense monolayer packing, methylene blue occupied a molecular area of $25 \AA^{2}$. On the other hand, Kipling and Wilson (1960) argued that the least possible projected area of methylene blue was $39.5 \AA^{2}$, which seemed to be more reasonable as $25 \AA^{2}$ was the projected area of the benzene ring which formed only part of the dye. In the present calculation, the value of $a_{1}$ is taken as $39 \cdot 5 \AA^{2}$.

By including the experimental value of $x_{m}$ in (4), the surface area $S$ of each clay is determined. Constant $K$ in (3) is approximately related to the heat of adsorption as

$$
K=A \cdot \exp (Q 1-Q 2 / R T)
$$

where $Q 1-Q 2=Q$ is the net heat of adsorption in calories per mole, $A$, the constant (assumed to be as 1.0 ), and $R$, the 2 calories. On rearranging (5), we get

$$
Q=2 \cdot 303(\log K) \times 2 \times T \text { cals } / \mathrm{mol} \text {. }
$$

Hence, knowing the value of $K$, at room temperature $T$, the net heat of adsorption $Q$ for each clay is determined.

\section{Experimental}

China clay, fire clay and bentonite of Indian origin were used in the present study. All the clays used were raw and finely ground. The basic dye methylene blue (MB) was used for adsorption. The initial concentration of the dye used for each adsorption was approximately $0 \cdot 1(\mathrm{M})$. MB dye of this concentration was then added to approximately $1 \mathrm{~g}$ of each clay taken in a series of test tubes. Different volumes of dye were added for each set of experiments. Dye and clay mix diluted to equal volumes for each set with distilled water was stirred for a while and allowed to settle for about $2 \mathrm{~h}$ to attain equilibrium. This clay and dye suspension was then centrifuged at 10,000 rpm using a high speed attachment. The supernatant liquid was transferred to another test tube and diluted (if necessary) so that the solution gave \% transmission above $50 \%$ for which the present absorptiometer instrument was set up. Finally, the concentration of the supernatant liquid after adsorption was measured using standard absorptiometer (one cell system, Hilger Pattern Biochem. absorptiometer) technique using $610 \mathrm{~m} \mu$ wavelength of light. The amount of dye adsorbed by rarious clays in each set of experiments was thus calculated from the fall in concentration of the dye solution.

The adsorption isotherms of the clay samples were drawn from the experimental values of the amount of dye added and the amount absorbed. Finally, the specific 
surfaces and heat of adsorption were determined from BET plotting of the adsorption isotherm (3). To compare the results of the present technique, specific surfaces of the clays were also measured by the standard BET gas-adsorption method.

\section{Results and discussions}

The physico-chemical properties of the clays used in the present study are shown in table 1.

The adsorption isotherms of all the three clays are shown in figures $1 \mathrm{a}-\mathrm{c}$. From these figures, it may be noted that the isotherms are all approximates of type 1 among four types of isotherm curves in Van der Waal's adsorption involving multilayer formation at low temperatures. BET plotting (3) of the adsorption isotherms are shown in figures $2 \mathrm{a}-\mathrm{c}$. From the slope and interception of figures $2 \mathrm{a}-\mathrm{c}$, the quantity of adsorbate $\left(x_{m}\right)$ required for a complete monolayer on the solid and constant $K$ are calculated for all the three clays used in this study. Then, applying (4), the surface area $S$ of all the clays is determined by having the experimental value of $x_{m}$ and constant values of $N$ and $a_{1}$. The results obtained by the present technique are given in table 2.

Table 2 also shows the surface area measured by standard gas-adsorption technique which is considered to be the most accurate and accepted method. It may be observed from table 2 that the results of both the methods are comparable and about $10-20 \%$ of lower values are obtained by the dye-adsorption technique. This is probably due to the high molecular area of the dye which prevented the dye particles to enter into the crevices of the area lower than the molecular area of the dye. The relative specific surface values of all the three clay samples are in agreement with their plasticity behaviour and the plastic clay bentonite is found to have maximum surface.

The heat of adsorption values (table 2) calculated from (6) indicate that the values are lower than $4.0 \mathrm{Kcals} / \mathrm{mol}$ for all the three clays and this shows that the adsorption processes in the present study are not of the chemisorption type which would have resulted in higher values than $4.0 \mathrm{Kcals} / \mathrm{mol}$.

Table 1. Physico-chemical properties of the clays.

\begin{tabular}{|c|c|c|c|}
\hline Properties & China clay & Fire clay & Bentonite \\
\hline $\begin{array}{l}\text { Chemical analysis } \\
\text { (major constituents, } \% \text { ) }\end{array}$ & $\begin{array}{l}\mathrm{SiO}_{2} 45 \cdot 78 \\
\mathrm{Al}_{2} \mathrm{O}_{3} 42 \cdot 16 \\
\mathrm{CaO}+\mathrm{MgO} 0 \cdot 54 \\
\text { L.O.I } 12 \cdot 83\end{array}$ & $\begin{array}{r}44 \cdot 06 \\
38 \cdot 52 \\
1 \cdot 36 \\
14 \cdot 90\end{array}$ & $\begin{array}{r}38 \cdot 91 \\
29 \cdot 35 \\
8 \cdot 43 \\
22 \cdot 75\end{array}$ \\
\hline $\begin{array}{l}\text { Mineralogical } \\
\text { characterization }\end{array}$ & Mainly Kaolinite & $\begin{array}{l}\text { Mainly Kaolinite } \\
\text { with some free } \\
\text { quartz }\end{array}$ & $\begin{array}{l}\text { Mainiy montmorillonite with } \\
\text { about } 10-15 \% \mathrm{Ca} \text { and } \mathrm{Mg}- \\
\text { carbonates }\end{array}$ \\
\hline Plastic behaviour & Highly plastic & plastic & Highly plastic \\
\hline DTA/DTG & at 550 to $650^{\circ} \mathrm{C}$ & at 600 to $650^{\circ} \mathrm{C}$ & $\begin{array}{l}\text { Main peak at } 160-200^{\circ} \mathrm{C} \text {, } \\
\text { second peak at } 550^{\circ} \mathrm{C} \text {, third } \\
\text { at } 650^{\circ} \mathrm{C} \text { and fourth at } 850^{\circ} \mathrm{C}\end{array}$ \\
\hline Colour & Perfectly white & Greyish black & Buff colour \\
\hline
\end{tabular}



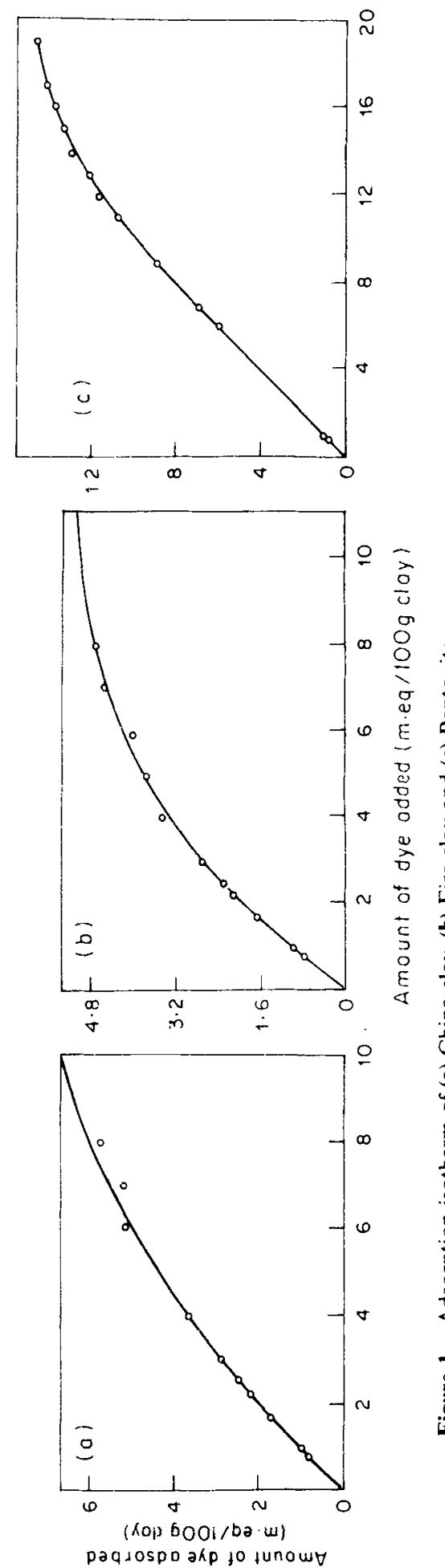

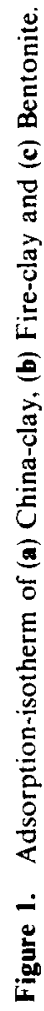



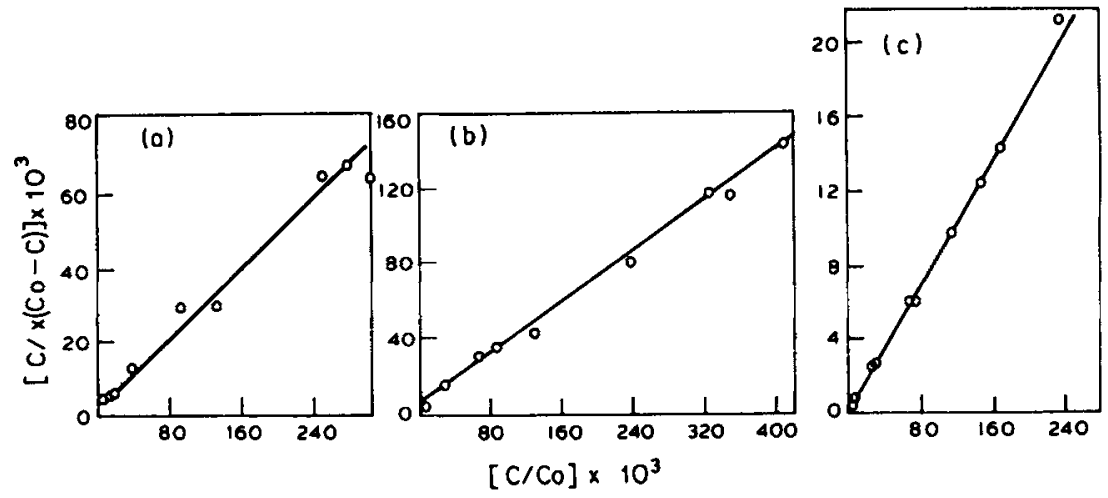

Figure 2. BET plot of (a) China-clay, (b) Fire-clay and (c) Bentonite.

Table 2. Specific surface and heat of adsorption values of the clays used in this study.

\begin{tabular}{lccc}
\hline & \multicolumn{2}{c}{ Specific surface $\left(\mathrm{m}^{2} / \mathrm{g}\right)$} & \\
\cline { 2 - 3 } Name of the clay & $\begin{array}{c}\text { Present } \\
\text { dye-adsorption } \\
\text { technique }\end{array}$ & $\begin{array}{c}\text { Gas-adsorption } \\
\text { technique }\end{array}$ & $\begin{array}{c}\text { Heat of adsorption } \\
\text { (Kcals/mol) }\end{array}$ \\
\hline China clay & 9.45 & 11.25 & 2.90 \\
Fire clay & 7.05 & 8.80 & 2.55 \\
Bentonite & 28.54 & 31.70 & 3.80 \\
\hline
\end{tabular}

\section{Conclusions}

The calculated heat of adsorption values for all the clays confirms physical adsorption and hence BET plotting of basic dye adsorption isotherms may be applicable in determining specific surfaces of clays. The specific surfacés measured by dye-adsorption technique lie within $10-20 \%$ of the gas-adsorption values and the present results can be utilized safely for comparison although the gas-adsorption result is more accurate.

\section{Acknowledgement}

The authors acknowledge the helpful discussions they had with Prof. N K Mitra, Department of Chemical Technology of Calcutta University.

\section{References}

Amerongen H Van 1967 in Science of ceramics (London and New York: Academic Press) 353

Boardman G and Worrall W E 1965 in Science of ceramics (London and New York: Academic Press) 247

Brunauer S, Emmett P H and Teller E 1938 J. Am. Chem. Soc. 60309

Dyal R S and Hendricks S B 1950 Soil Sci. 69421

Ewing W W and Rhoda R N 1950 Anal. Chem. 221453

Faruqui F A, Susumu O and Williamson W O 1967 Clay Miner. 719 
Gand G 1989 Bull. Liaison Lab. Ponts Chaussees 16185

Kipling J J and Wilson R B $1960 \mathrm{~J}$. Appl. Chem. 10109

Lautrin D 1989 Bull. Liaison Lab. Ponts Chaussees 16053

Maron S H. Bobalek E G and Fok S $1956 \mathrm{~J}$. Colloid Sci. 1121

Orr C J R and Dallavalle J M 1959 Fine particle measurement, (New York: Macmillan) Chap 8221

Turkdogan E T, Olsson R G and Vinters J V 1970 Carbon (Great Britain: Pergaman Press) 8545

White D and Cowan C T 1960 Trans. Br. Ceram. Soc. 5916

Worrall W E 1958 Trans. Br. Ceram. Soc. 57210

Yariv S, Ghosh D K and Helper L G 1991 J. Chem. Soc. (Faraday Trans.) 871201 